\title{
Where do sea lions live? How interspecific interactions and abiotic factors predict Steller sea lion habitat selection
}

\author{
Prashanna Pokharel \& Megan Hansen \\ Department of Biological Sciences, University of Alberta, Edmonton, Alberta \\ Corresponding author: mhansen@ualberta.ca
}

\section{ABSTRACT}

Habitat selection by species is dependent on both abiotic factors and species interaction. With regards to species interaction, competition and facilitation can play a critical role regarding how a species selects its habitat. Previous work has suggested that Steller sea lions (Eumetopias jubatus) have been displaced from their haulout sites due to competition with California sea lions (Zalophus californianus). The purpose of our study is to understand what factors determine the number of Steller sea lion present at a haul out site in the Barkley Sound area in Bamfield, BC. We tested this by asking if the number of Steller sea lions at a haulout site at a certain time is related to the presence of California sea lions (as a proxy for interspecific interaction), time of day, and tide height or a combination of two or three of these variables. After running a generalized mixed effect model and competing our models using Akaike Information Criteria, our results indicated that tide height was the best predictor for explaining the number of Steller sea lions present at a haulout site. However, our results also indicated that the presence of California sea lions and time of day may play a role in determining Steller sea lion haulout sites as well. We found from this study that both species interaction and abiotic factors need to be collectively considered when predicting the mechanisms underlying species habitat choice in marine ecosystems.

\section{Introduction}

Many factors affect species habitat selection in marine ecosystems. However, research commonly focuses on the role of abiotic factors with regards to habitat choice, rather than species interactions? (Byholm et al., 2012). Collectively focusing on both abiotic factors and species interactions can help us to better understand habitat choice and therefore better characterize species distribution (Hamilton, 2010). One key species interaction to consider is competitive exclusion, the exclusion of one species by a more dominant species when resource requirements are

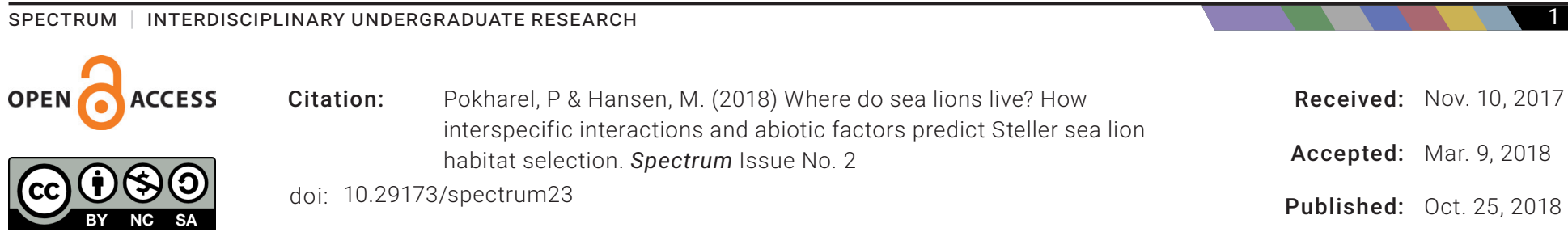


similar (Hardin, 1960). This competition is largely responsible for the success of a species at a given habitat, as it determines whether that species will be able to persist in that location. Nillison et al. 2004 found that in some cases, the presence of competition might outweigh any landscape or physical factors when determining habitat selection. For this reason, to correctly characterize habitat choice and species distribution, this interspecific interaction cannot be ignored.

The effect of competitive exclusion on species distribution has been demonstrated by Steller sea Iion (Eumetopias jubatus) populations. In the past, they have been displaced at the Channel Islands by California sea lions (Zalophus californianus), a closely related species (Bigg, 1985). Both species of sea lions have similar resource requirements, including preferred prey (Olesiuk and Bigg, 1988), which precipitates competitive exclusion. The opposite interaction to competition is facilitation, which is the enhanced performance of a species due to the presence of another (Callaway, 2007). Depending on the balance of species density and resources, either facilitation or competition are able to occur (Mesgaran et al., 2017; Gause, 1936). Facilitation has been suggested to occur in other areas, but this occurrence has less support for sea lions off the west coast of Vancouver Island (Bigg, 1985), the location of the population in our study.

The influence of interspecific interactions is relevant to this species habitat selection, as populations of California sea lions have recently begun to migrate further north to British Columbia (Bigg, 1985), a location that hosts $16 \%$ of the world's Steller sea lion population (Fisheries and Ocean Canada, 2010). It is possible that California sea lions will change the habitat selection of the British Columbia population of Steller sea lions in a way similar to that of the Channel Island populations (Bigg, 1985). Specifically, a change in habitat selection of haulout sites is of interest (Ban, 2005). Haulout sites are terrestrial areas for sea lions to mate, rest, and escape marine predators (Moultona et al., 2000). For this reason, haulout sites are an important part of sea lion habitat and are listed as a "critical habitat" of Steller sea lions, according to the Endangered Species Act (Ban, 2005). This critical habitat is defined as an area that would be detrimental to the survival of the species if lost (Littell, 1992); therefore alterations in haulout site selection due to competition have the potential to greatly affect the Steller sea lion distribution. Despitethis importance, much still remains unknown about the interspecific interactions affecting sea lions' preferred haulout site (Ban, 2005).

In contrast, much of past research has focused on characterizing several abiotic factors affecting haulout site selection (Ban \& Trites, 2007; Ban, 2005; Bigg, 1985). Some of these predicting factors include tide height and time of day, with the greatest number of Steller sea lions at a given site occurring during low tide and midday respectively (Calambokidis et al., 1987). The purpose of our study is to understand if the presence of California sea lions (as a proxy for interspecific interaction) at haulout sites in Barkley Sound affects Steller sea lion abundance at those respective sites. Furthermore, this study aims, to compare this interspecific interaction with currently known predicting factors for the number of Steller sea lions at haulout sites on the British Columbia coast. Adding in this new factor will provide further knowledge regarding the extent to which competition affects habitat selection.

We hypothesize that the best model to predict the number of Steller sea lions at a haulout site will include tide height, time of day, and presence or absence of California sea lions. Additionally we predict that the greatest abundance of Steller sea lions will be present at low tide, midday, and when California sea lions are not present. This prediction is grounded in past research suggesting low tide heights allow for sea lions to best access the haulout sites, as well as observational data regarding sea lion haulout and time of day (Calambokidis et al., 1987). Our prediction that the number of Steller 
sea lions at a haulout site will be highest when California sea lions are not present stems from similar studies regarding competitive exclusion (Kaspersson et al., 2012; Byholm et al., 2012) as well as previous data on sea lion distribution on the British Columbia coast (Bigg, 1985). For example, Kaspersson et al. (2012) demonstrated a similar interspecies interaction in brown trout habitat selection. They demonstrated that brown trout choose habitat away from competitors, even at the price of preferred resources. Additionally, past research using an aerial survey suggests that it is uncommon to observe the two different sea lion species at a haulout site together off the Western coast of Vancouver Island (Bigg, 1985).

Correctly identifying the best way to predict Steller sea lion haulout sites is crucial to making predictions of their population distribution (Hamilton, 2010). Steller sea lions play a significant role in the marine environment because they are one of the top marine predators and act as an indicator species for the general status of coastal marine ecosystems due to their wide distribution and long life spans (Fisheries and Ocean Canada, 2010). They have also been listed as "NearThreatened Species" by the International Union for Conservation of Nature (Fisheries and Ocean Canada, 2010); therefore, correctly characterizing their habitat also has implications regarding the suitable focus of conservation efforts (Ban and Trites, 2007). Lastly, Lyman (1988) found that some haulout sites have been used for more than four centuries, indicating that the factors sea lions use for haulout selection are likely to be stable. This further suggests the importance of characterizing haulout site selection as any change in site may suggest instability in one of the predicting factors. Because all of these implications depend on the correct identification of haulout site, using the best model to predict habitat selection is crucial. For this reason, considering both abiotic factors and interspecific interactions is imperative.

\section{Methods}

Data Collection

Data was collected via line transect surveys from August 1-10, 2017. Two line transects were designated in Barkley Sound, Bamfield, BC. Transect 1 ran parallel to the coastline of the Deer Group Islands. Transect 2 ran parallel to the coastline starting at Bamfield Inlet and ending at Pachena Lighthouse (Figure 1). Data was only recorded from the site of the boat facing the coastline. The transects were located approximately $100 \mathrm{~m}$ off the coast to avoid reefs, and travelling at a speed of 5-6 knots. During surveys, sea lion haulout sites were located and the Universal Transverse Mercator (UTM) coordinates for each site were recorded. Each sighting of Steller sea lions and California sea lions was recorded, as well as the bearing to the site, the number of individuals observed at the site, and the time of day of the sighting. We located four haulout sites on Transect 1 and three on Transect 2 for a total of seven Steller sea lion haulout sites in Barkley Sound (Figure 1).

We formed three overarching hypotheses with eight underlying hypotheses based on the ecology of Steller sea lion haulout sites (Table 1). We hypothesized that the number of Steller sea lions present at a haulout site will be related to time of day (TOD), tide height, and the presence or absence of California sea lions, or a combination of these variables. Each of our observations (n) was collected at a different time of day. California sea lions are not present. This prediction is grounded in past research suggesting low tide heights allow for sea lions to best access the haulout sites, as well as observational data regarding sea

\section{Steller sea lions}

Our response variable was the number of Steller sea lions present at a haulout site at a specific time of day. Every time we approached a haulout site during our transects, we counted and recorded 


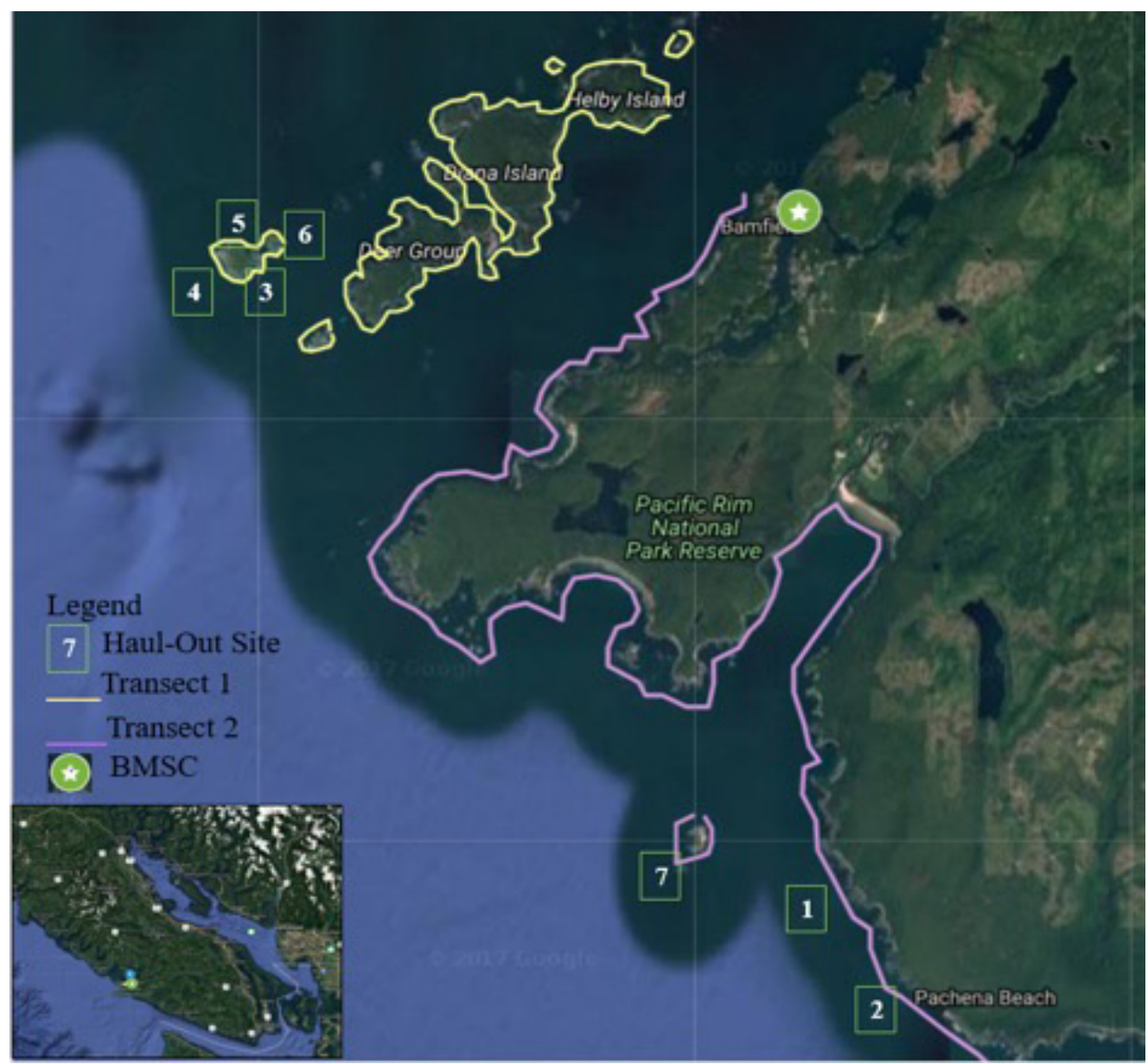

Figure 1: Transect locations along the Deer Group Islands and Pachena Beach Coastline in Barkley Sound BC, Canada. The Seven Steller sea lion haul-out site locations are also delineated along both Transect 1 and Transect 2 (Google Maps 2017).

the number of Steller sea lions that were present hauling out on the rocks or swimming nearby close to the rocks.

\section{California sea lions}

Our first explanatory variable was California sea lions (as a proxy for interspecific interaction). For each of our observations, we observed and recorded the presence (1) or absence (0) of California sea lions at Steller sea lion haul out sites.

\section{Tide height}

Our second explanatory variable was tide height. We were unable to directly measure tide height during our transect. Instead, we used the daily index for times and heights for high and low tides provided by Fisheries and Oceans Canada for Bamfield, BC for each one of our transect days (http://www.tides.gc.ca/eng/station?sid=8545).

\section{Time of day}

Our third explanatory variable was included to account for the fact that the number of Steller sea lions at a haulout site may vary depending on what time of the day it is. During each of our transects, we noted the time of our observation. To prevent pseudoreplication for time of day in our observation (n), we negated any observations that had similar time of days. 
Data Analysis and Model Fitting

All data analysis and model fitting was performed using R (v.3.4.1, R Core Team, 2013) with GUI RStudio (v1.0.143) using packages lattice (Sarkar 2015), Ime4 (Bates et al., 2015) and AICcmodavg (Mazerolle, 2017).

We used the protocols provided by Zuur et al. (2010) to explore our data. We checked for the presence of any outliers, collinearity and calculated the variance inflation factors for our explanatory variables (see results for outputs of data exploration). The poisson distribution best fit the distribution of our data because it was not normally distributed or over dispersed (Zurr et al., 2009).

We used generalized linear mixed effect models ( $\mathrm{glmm})$ to test for the effects of tide height, time of day and presence or absence of California sea lions on the number of Steller sea lions present. Tide height, time of day and presence or absence of California sea lions were included as fixed effects. We chose to use glmm specifically to account for spatial covariation. This was necessary because our study site was a repeated measure and thus the data points were not independent (Zurr et al., 2009). We surveyed the same sites several times at different times of day; therefore, using this model would account for non-independence in our observations (Zurr et al., 2009). We created eight different models (Table 1) and ran this mixed effect model using the "glmer" function in Rstudio. We then competed our 8 models using the Akaike Information Criterion (AIC) to determine which of our fixed effects best explained the number of Steller sea lions present. The AIC allows us to determine the quality of each model. We compared models using AIC, $\triangle \mathrm{AICs}$ (where $\triangle \mathrm{AIC}<2$ is considered to have substantial support) and AICwt (probability of which model is the best out of the candidate set) (Zurr et al., 2009) to find the best fit model.

\section{Results}

To test if the presence of California sea lions (CALI), time of day (TOD) and tide height affects the number of Steller sea lions at a haulout site, we tested eight specific hypotheses (Table 1).

Prior to creating our linear models, we checked to see if there were any significant relationships between our explanatory variables. If the explanatory variables correlate, collinearity can exist which would suggest that the presence of California sea lions, time of day or tide height partially explain each other. We used Pearson's correlations coefficient ( $r$ ) to examine collinearity among our explanatory variables. There was weak collinearity between all three variables (TOD \& TIDEHEIGHT $r=0.51, p=0.032 ;$ TOD \& CALI $r=-0.26, p=0.054$; CALI \& TIDEHEIGHT $r=-0.03, p=0.008)$. Furthermore, we checked for variance inflation factors (VIF), which detect multicollinearity between our variables. Multicollinearity can exist if linear relationships exist between our explanatory variables and can cause problems as those variables are not independent anymore. For our explanatory variables, VIF were low values $(T O D=1.613980, \quad C A L I=1.098038$, TIDEHEIGHT=1.505847). Therefore, this negates any possible sources of error and we included all three variables in our statistical model

From our 'glmer' models and competing them using AIC, results showed that model 5 which included only tide height as a fixed effect had the most substantial and empirical support (Table 2, Table 3). The AIC for this model was 171.6 and it was the lowest value. Furthermore, the AIC weight for this model was 0.52 ; therefore, 52 percent of the weighted evidence suggests that this is the best model to describe our data. The $\triangle \mathrm{AIC}$ for model 5 was 0 , which showed substantial support for the model. The intercept for model 5 was 2.560 and there was a positive relationship between tide height and the number of Steller sea lions present at a given time (Figure 2). The intraclass correlation factor was 0.001 , confirming that there was no significant 
Table 1: Model hypothesis surrounding explanatory variables (presence/absence of California sea lions, tide height, and time of day) affecting the response variable, abundance of Steller sea lions in Barkley Sound, BC. Site is included as a random effect. STELL $=$ Number of Steller sea lions on haulout site. CALI= Presence of absence of California sea lions on haulout site. TOD = Time of Day at haulout site. TIDEHEIGHT = Tide height near haulout site in meters.

\begin{tabular}{|l|l|l|}
\hline Model \# & Model Hypothesis & Model \\
\hline Mod 1 & $\begin{array}{l}\text { Steller sea lion abundance is affected } \\
\text { by the presence or absence of Califor- } \\
\text { nia sea lions }\end{array}$ & STELL CALI+(1|SITE) \\
\hline Mod 2 & $\begin{array}{l}\text { Steller sea lion abundance is affected } \\
\text { by the presence or absence of Califor- } \\
\text { nia sea lions and the time of day. }\end{array}$ & STELL CALI+TOD+(1|SITE) \\
\hline Mod 3 & $\begin{array}{l}\text { Steller sea lion abundance is affected } \\
\text { by the presence or absence of Cal- } \\
\text { ifornia sea lion, time of day and tide } \\
\text { height. }\end{array}$ & $\begin{array}{l}\text { STELL CALI+TOD+TIDE- } \\
\text { HEIGHT+(1|SITE) }\end{array}$ \\
\hline Mod 4 & $\begin{array}{l}\text { Steller sea lion abundance is affected } \\
\text { by the time of day. }\end{array}$ & STELL TOD+(1|SITE) \\
\hline Mod 5 & $\begin{array}{l}\text { Steller sea lion abundance is affected } \\
\text { by tide height. }\end{array}$ & STELL TIDEHEIGHT+(1|SITE) \\
\hline Mod 6 & $\begin{array}{l}\text { Steller sea lion abundance is affected } \\
\text { by tide height and time of day. }\end{array}$ & STELL TIDEHEIGHT+TOD+(1|SITE) \\
\hline Mod 7 & $\begin{array}{l}\text { Steller sea lion abundance is affected } \\
\text { by tide height and the presence or } \\
\text { absence of California sea lions. }\end{array}$ & STELL TIDEHEIGHT+CALI+(1|SITE) \\
\hline Mod 8 & $\begin{array}{l}\text { Steller sea lion abundance is affected } \\
\text { by the time of day and the presence or }\end{array}$ & STELL TOD+CALI+(1|SITE) \\
\hline
\end{tabular}

collinearity among the sites (our random effect). Although model 5 had the highest AIC, models 6 and 7 each carried approximately 20 percent of the weighted evidence (AlCwt of model 6= 0.21 , AlCwt of model 7=0.19) (Table 2, Table 3). Each of these models included the variable tide height, furthering our inference that tide height is the best predictor of Steller sea lion abundance.

\section{Discussion}

Our results suggest that abiotic factors (ie. tide height) best predict habitat selection. Tide height was in all of our top three models (model 5,6 \& 7). However, temporal factors (ie. time of day) and interspecific interactions (ie. presence of California sea lion) also have the potential to affect habitat selection, and we cannot exclude them. Almost $100 \%$ of our AIC weight is held in models 5 , 6 , and 7 meaning that they are the best models of the candidate set (Table 2). Thus, all of these need to be considered when predicting the number of Steller sea lions present at a haul out site.

As mentioned above, tide height was part of all 3 of our top models, including the model carrying $52 \%$ of the AIC weight. Our results therefore suggest that tide height is a strong predicting factor of Steller sea lion haulout site selection. However, the directionality between tide height 


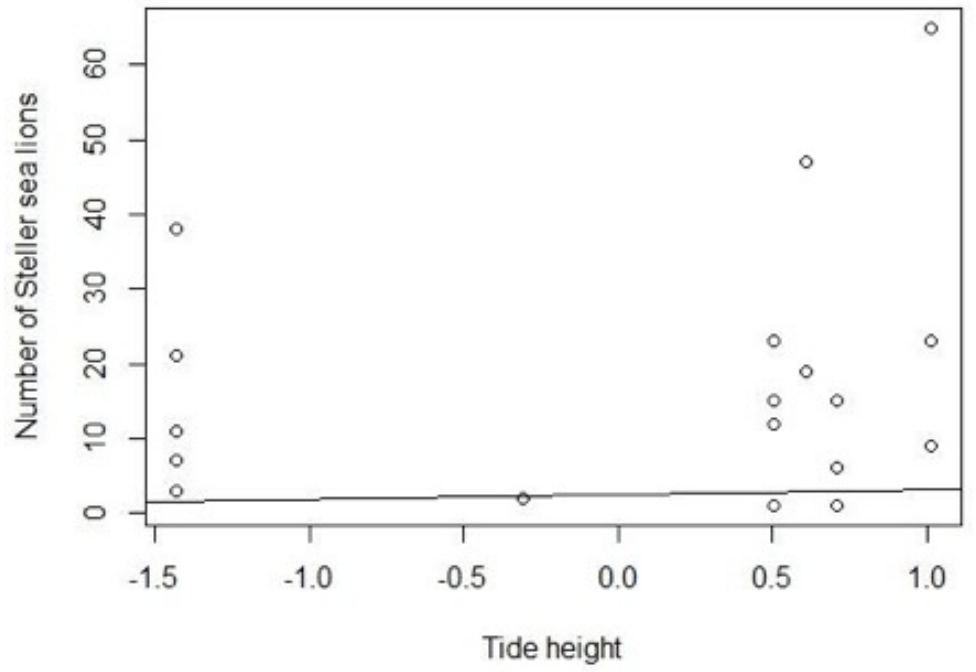

Figure 2: Output of model 5; Number of Steller sea lions present at a haulout site and the corresponding tide height $(\mathrm{m})$ in Barkley Sound region, British Columbia. (Effect size $=0.640$, Intercept $=2.56, \mathrm{P}$-value $=0.0069$ ) and number of Steller sea lions is not the same as we predicted (Figure 2). Instead, tide height had weak positive effect size (Table 3 ) on number of Steller sea lions at a site. This means that a higher tide predicts more sea lions at a haul out site. In contrast, primary literature suggests that sea lions are more likely to haul out at low tide due to easier site access (Calambokidis et al., 1987); however, a high tide did not appear to restrict sea lion access to haulout sites in our study. A possible explanation for this result is that when haulout sites have steep intertidal zones, a high tide does not rapidly impede the amount of haulout space available, thus sea lions can remain hauled out even out at high tide (Ban \& Trites, 2007). This could have potentially occurred in our study, but since we did not characterize this aspect of haulout site topography, we cannot formally make this conclusion. Alternatively, because this result is incongruent with currently accepted literature regarding tide height and haulout site, it may instead be an artefact of our small sample size.

Interspecific interactions between the California and Steller sea lions are part of the model carrying $19 \%$ of the AIC weight (model 7 ). This means $19 \%$ of the evidence weight suggests the presence or absence of California sea lions, along with tide height, predicts the number of Steller sea lions at a haulout. Although this AIC weight is smaller than the top model, which had tide height as the lone predictor (Model 5: AICwt = .52), we cannot ignore model 7, as its AIC weight is still substantial. Additionally, California sea lions were found to have a weak positive effect size (Table 3) with number of Steller sea lions. This does not support our initial hypothesis regarding competitive exclusion. Instead, this effect size suggests that there may be a weak signal for facilitation, meaning there might be a benefit for California sea lions and Steller sea lions to coexist. Likely this facilitation is due to the presence of a larger group providing a defense against predation or physiological stress (Stachowicz, 2001). However, previous research has found facilitation is density-dependant and that higher densities reduce the possibility of facilitation (Mesgaran, 2017). This means that it could also be possible that as a greater number of California sea lions expand their spatial range further north to British Columbia, density may increase to the point where this relationship shifts from facilitation to competition. Additionally, Gause (1936) demonstrated that complete exclusion does not occur when sufficient resources are available. With regard to the two sea lion species and their haulouts, space availability is the resource, and if this resource is not limited, then the two sea lion species can coexist. Our 
Table 2: Akaike information criterion table showing performance of candidate generalized linear mixed effect model sets for predicting number of Steller sea lions present at haulout sites in Barkley Sound, BC, Canada. (K= Numbers of parameters, $\mathrm{AIC}=$ Akaike information criterion, $\triangle \mathrm{AIC}=$ Difference between $\mathrm{AIC}$ values of smallest $\mathrm{AIC}$ and each subsequent model, AICWt= Akaike weights, LL= Log-likelihood, Cum.Wt= Cumulative weights). (See Table 1 for each model details)

\begin{tabular}{|l|l|l|l|l|l|l|}
\hline Model & K & AIC & $\Delta$ AIC & AICWt & LL & Cum.Wt \\
\hline Mod5 & 3 & 171.6 & 0 & 0.5200 & -82.81 & 0.5200 \\
\hline Mod6 & 4 & 173.4 & 1.831 & 0.2081 & -82.72 & 0.7282 \\
\hline Mod7 & 4 & 173.5 & 1.967 & 0.1945 & -82.79 & 0.9227 \\
\hline Mod3 & 5 & 175.4 & 3.812 & 0.07730 & -82.71 & 1.000 \\
\hline Mod4 & 3 & 206.1 & 34.55 & $1.634 \mathrm{E}-08$ & -100.0 & 1.000 \\
\hline Mod2 & 4 & 207.4 & 35.87 & $8.450 \mathrm{E}-09$ & -99.74 & 1.000 \\
\hline Mod8 & 4 & 207.5 & 35.87 & $8.450 \mathrm{E}-09$ & -99.74 & 1.000 \\
\hline Mod1 & 3 & 225.5974 & 53.98635157 & $9.84 \mathrm{E}-13$ & -109.799 & 1 \\
\hline
\end{tabular}

Table 3: Effect sizes of the highest weighted models from Akaike information criterion to determine the variables that best predict the presence of Steller sea lions in haulout sites in Barkley Sound, BC. (See table 1 and 2 for generalized mixed effect model details)

\begin{tabular}{|l|l|l|l|}
\hline Model number & Fixed effect & Effect size & P-value \\
\hline $\mathbf{5}$ & Tide height & 0.640 & 0.00690 \\
\hline $\mathbf{6}$ & Tide height & 0.670 & 0.00579 \\
\hline $\mathbf{6}$ & Time of day & -0.0302 & 0.0560 \\
\hline $\mathbf{7}$ & Tide height & 0.644 & 0.00217 \\
\hline $\mathbf{7}$ & Presence of California sea lion & 0.0150 & 0.008 \\
\hline
\end{tabular}


results suggest that California sea lions have not reached the density required to make this resource scarce, and thus competitive exclusion may not be occurring yet in the area we studied.

Time of day was also present in one of our top 3 models (model 6) with an AIC weight of 0.21 Time of day had a small negative effect size Table $3)$; therefore, we have weak evidence to suggest that there may be more Steller sea lions present at haulout sites earlier during the day. Further research with alternative data collection methods is required to reach a more concise conclusion. However, due to it being part of a model which holds $21 \%$ of evidence, it is an important aspect of habitat selection that should be still be considered moving forward. Similar studies suggest that time of day is a factor that affects Steller sea lions at their haulout sites via multiple factors, including boat traffic (Calambokidis et al.,1987) and foraging times (Loughlin et al., 2013).

Our results illustrate the importance of including interspecific interactions in models predicting habitat selection. Even though our best fit model (model 5) did not include interspecific interaction, we cannot ignore this factor, as our model that held $20 \%$ of AIC weight did have interspecific interaction as a predictor (model 7 ). This result supports the growing body of research stressing the importance of including these interactions in habitat selection models (Byholm et al., 2012). Despite this contribution, our experiment did have significant limitations. These include a small sample size, which may account for the lower effect of California sea lions than expected, as we may not have collected enough samples to adequately represent this factor. Additionally, the time of day variable was compressed due to boat driver availability, thus samples were only taken from a small proportion of a total day.

Regardless of these limitations, our study suggests promising directions for future work. By increasing sample size and variation in time of day of sampling, it may be possible to more accurately determine which of our 3 top models is best. Recording the density and number of California sea lions present, rather than just their presence or absence, may give us more accurate results. These results would allow the density dependent aspect of species interactions to be monitored, as primary literature suggests that density is a determining factor regarding whether a given relationship will result in competition or facilitation (Mesgaran et al., 2017). Therefore future research may find that the interaction between California sea lions and Steller sea lions changes to competition at high-density sites, ultimately resulting in different haulout selection. However, irrespective of the relationship type (facilitation or competition), both end-results suggest that interspecific interactions must be considered in order for models of habitat selection to be adequate.

In conclusion, both species interaction and abiotic factors need to be collectively considered when predicting the mechanisms underlying species habitat choice in marine ecosystems. With regard to species interaction, competition and facilitation may both be playing a role in habitat selection. Our study found that haulout sites of Steller sea lions can be predicted by a combination of factors such as species interaction (presence of California sea lions), tide height, and time of day. Additionally our results suggest the importance of fully exploring each predicting factor. This is because a factor that has small predicting value in a model, such as the model including interspecific interactions (presence of California sea lions), may have a large impact biologically and should still be considered. Taken together, these findings suggest the many factors that need to be considered when formulating models for ecological theories, in order for the model to accurately characterize the desired ecological phenomenon. 


\section{Acknowledgements}

We would like to thank our professor Dr. Jason T. Fisher and teaching assistant Christy James for their continuous support and supervision through this short term project. We would also like to thank the Bamfield Marine Sciences Centre for giving us the opportunity and the necessary tools required to conduct field work near the islands of Barkley Sound. We acknowledge Laura Newberry for assisting us with field work, cleaning data and mapping. Lastly, we would like to acknowledge all of our classmates in Survey Methods for Coastal Wildlife 2017 for their continuous support during this course and research project.

\section{References}

Ban, S. S. (2005). Modeling and characterization of Steller sea lion haulouts and rookeries using oceanographic and shoreline type data (Master's Thesis). University of British Columbia, Vancouver, Canada.

Ban, S., \& Trites, A. W. (2007). Quantification of terrestrial haul-out and rookery characteristics of Steller sea lions. Marine Mammal Science, 23(3), 496-507. https://doi.org/10.1111/j.17487692.2007.00130.x

Bigg, M. A. (1985). Status of the Steller sea lion (Eumetopias jubatus) and California sea lion (Zalophus californianus) in British Columbia. Canadian Journal of Fisheries and Aquatic Sciences, 77, 20.

Byholm, P., Burgas, D., Virtanen, T., \& Valkama, J. (2012). Competitive exclusion within the predator community influences the distribution of a threatened prey species. Ecology, 93(8), 1802-1808. https://doi.org/10.1890/12-0285.1

Calambokidis, J., Taylor, B. L., Carter, S. D., Steiger, G. H., Dawson, P. K., \& Antrim, L. D. (1987). Distribution and haul-out behavior of harbor seals in Glacier Bay, Alaska. Canadian Journal of Zoology, 65(6), 1391-1396. https://doi.org/10.1139/z87-219

Callaway, R. M. (2007). Positive Interactions and Interdependence in Plant Communities. Dordrecth, The Netherlands: Springer.

Fisheries and Oceans Canada. 2010. Management Plan for the Steller Sea Lion (Eumetopias jubatus) in Canada [Final]. Species at Risk Act Management Plan Series. Fisheries and Oceans Canada, Ottawa.

Gause, G. F. (1936). The struggle for existence. Soil Science, 41(2), 159.

Hamilton, I. M. (2010). Habitat selection. In M.D. Breed \& J. Moore, Encyclopedia of Animal Behavior (3843). Amsterdam, The Netherlands: Elsevier.

Hardin, G. (1960). The Competitive Exclusion Principle. Science, 131(3409), 1292-1297. https://doi. org/10.1126/science.131.3409.1292

Kaspersson, R., Höjesjö, J., \& Bohlin, T. (2012). Habitat exclusion and reduced growth: a field experiment on the effects of inter-cohort competition in young-of-the-year brown trout. Oecologia, 169(3), 733-742. http://doi.org/10.1007/s00442-012-2248-5.

Littell, R. (1992). Endangered and other protected species: Federal law and regulation. The gateway to environmental law, 185.

Loughlin, T. R., Merrick, R. L., Sease, J. L., \& York, A. E. (2003). Diving behaviour of immature Steller sea lions (Eumetopias jubatus). Fishery Bulletin, 566-582. 
Lyman, R. (1988). Zoogeography of Oregon coast marine mammals: The last 3,000 years. Marine Mammal Science, 4(3), 247-264. https://doi.org/10.1111/j.1748-7692.1988.tb00205.x

Mesgaran, M. B., Bouhours, J., Lewis, M. A., \& Cousens, R. D. (2017). How to be a good neighbour: Facilitation and competition between two co-flowering species. Journal of Theoretical Biology, 422, 72-83.

Moultona, V. D., Millera, E. H., \& Ochoa-Acunabc, H. (2000). Haulout behaviour of captive harp seals (Pagophilus groenlandicus): incidence, seasonality, and relationships to weather. Applied Animal Behaviour Science, 65(4), 367-378. https://doi.org/10.1016/S0168-1591(99)00062-3

Nillison, P. A., Huntingford, F. A., \& Armstrong, J. D. (2004). Using the functional response to determine the nature of unequal interference among foragers. Proceedings of the Royal Society B: Biological Sciences, 271(5), S334-S337. http://doi.org/10.1098/rsbl.2004.0170

Olesiuk, P. F., \& Bigg, M. A. (1988). Seals and sea lions in British Columbia. Department of Fisheries and Ban, S. S. (2005). Modeling and characterization of Steller sea lion haulouts and rookeries using oceanographic and shoreline type data (Master's Thesis). University of British Columbia, Vancouver, Canada.

R Core Team 2013. R: A language and environment for statistical computing. R Foundation for Statistical Computing, Vienna, Austria. URL http://www.R-project.org/.

Stachowicz, J. J. (2001). Mutualism, facilitation, and the structure of ecological communities: Positive interactions play a critical, but underappreciated, role in ecological communities by reducing physical or biotic stresses in existing habitats and by creating new habitats on which many species depend. American Institute of Biological Sciences, 51(3). https://doi.org/10.1641/00063568(2001)051[0235:MFATSO]2.0.C0;2

Zuur, A. F., Ieno, E. N., \& Elphick, C. S. (2010). A protocol for data exploration to avoid common statistical problems. Methods in Ecology and Evolution, 1(1), 3-14. https://doi.org/10.1111/j.2041-

210X.2009.00001.X 